\title{
The Application of "Abstraction and Concretion" in English Language and Literature Teaching
}

\author{
Chen Cheng \\ Institute of foreign languages, Fuzhou College of Foreign Studies and Trade, Fuzhou, Fujian 350202, China \\ chenchengfz@126.com
}

Keywords: abstraction and concretion; English language and literature teaching; applied research.

\begin{abstract}
The effective implementation of English language and literature teaching activities can not only help students to realize their knowledge of English, but also enhance their practical application ability of English knowledge. Moreover, it can cultivate students' cultural accomplishment and literary level. This paper analyzes and interprets the problem of abstraction and concreteness from the perspective of English language and literature teaching practice, and studies the basic principles of English language and literature teaching. This paper puts forward some effective strategies to optimize the teaching of English language and literature from three dimensions: the formulation of the teaching contents of English language and literature, the classroom interaction in the teaching of English language and literature, and the practical teaching mode of English language and literature. And then it realizes the research purpose of improving students' cognitive level of English knowledge and practical application ability from the angle of English language and literature teaching.
\end{abstract}

\section{Introduction}

Abstraction and concreteness are the two dimensions of the study of English language and literature teaching. They are the ways to explore the essence of teaching phenomena. They are also the scientific perspectives to solve the problems of English language and literature teaching and to improve the quality of English language and literature teaching. English language and literature teaching activities are carried out through the transmission of English cultural background knowledge to enable students to understand the basic meaning of English knowledge and extend the meaning, and through cross-cultural knowledge education to help students better apply English knowledge to practice. The key part of foreign language teaching activities is to grasp the practicality of English knowledge, while the practicality of English knowledge is shown in the connection between English basic knowledge and English cultural knowledge. Only when students get out of the shackles of English basic knowledge theory and fully integrate into the background of English cultural knowledge can they really grasp the practicality of English knowledge. English literature is an important way of presenting English culture. Teaching English knowledge to students through English literature teaching as the core approach can help students understand the basic knowledge of English more thoroughly and easily, and have a deeper understanding of its broad and extended meaning.

\section{The problem of abstraction and concretion in English language and literature teaching}

It is an important cross-cultural teaching method to teach students English knowledge from the perspective of English literature. In order to enable students to more fully and in-depth grasp of English knowledge at the same time also significantly improve the level of practical application of students' English knowledge. More importantly, through the process of students' English literature education activities, the students' cognitive level of the culture of the English-speaking countries and even the world culture is enhanced, and the students' cultural connotation and literary accomplishment are enriched. This dual teaching significance makes English language and literature teaching activities become a combination of knowledge education and quality education, which has 
important practical value in College education. Abstraction and concreteness is the key element in English language and literature teaching: the scope and effect of the educational value of English language and literature, and the research dimension is put forward. If the scope of the educational value of English language and literature is too broad, it will bring great pressure on students'cognitive thinking and make them think that the content of English language and literature is too abstract. If the scope of the excavation is too small, the students'cognition can only stay in the specific part of the surface of English language and literature, and can not be further extended to acquire its meaning, thus losing its teaching significance.

From the perspective of English language and literature teaching practice, there are two dimensions of "abstract and concrete" in English language and Literature Teaching in Colleges and universities. In the process of explaining English language and literature knowledge to students, many students can not fully understand English literature because of poor literary cognitive ability or inadequate literary analysis ability of teachers themselves. This makes students feel that the teaching content of English literature is too abstract and obscure. When students can not be interested in the content of English language and literature knowledge or can not effectively understand the premise, English language and literature teaching will lose its practical significance. The concrete problems in English language and literature teaching are contrary to the abstract ones. In the process of teaching, teachers simply transfer the "shallow" knowledge of English language and literature to students, such as the background knowledge of the writers of English language and literature, the theme content of the works, the basic historical background and geographical knowledge. Wait. These knowledge are the simple knowledge content that students can obtain by searching on the Internet on their own, and have no substantial educational significance to students. More importantly, the connotation of English language and literature is not transmitted to students. This makes the teaching of English language and literature unable to effectively achieve its basic teaching purposes, but also a waste of students' enthusiasm for learning and learning time.

\section{Teaching principles of English language and literature based on "abstract and specific" dimensions}

\subsection{The value of English language and literature education should be guided by the principle of effectiveness.}

In the process of choosing and compiling the teaching content, English language and literature teaching should not only be designed according to the teaching plan and the content of English language and literature works, but also be evaluated comprehensively according to the students' cognitive ability and their specific learning needs. Thus, the teaching contents of English language and literature can be fully acquired by students, and the expected teaching effect of English language and literature can be achieved. In the process of realizing the actual teaching effect, the connection between students' cognitive thinking and knowledge content is the most important. Therefore, teachers should respond to the teaching objectives in the excavation and selection of the educational value of English language and literature. Literary knowledge itself has a certain degree of abstraction. Literary knowledge of these majors is not the actual goal of English language and literature teaching. Therefore, the content of knowledge should be reasonably deleted from the target of the basic teaching task, so as to avoid excessive extension of the content of knowledge. Based on the breadth and depth of knowledge coverage of literary works, teachers should make a full and reasonable discrimination. Only by combining the scope of knowledge with the teaching objectives can the students acquire enough English language and literature teaching contents, avoid the emergence of "abstract" teaching phenomenon and ensure the effectiveness of teaching activities.

\subsection{The teaching practice of English language and literature should be guided by the principle of thoroughness.}

In order to ensure the realization of teaching effect in English language and literature teaching, we should maximize the interpretation of teaching content to students. The teaching content of English 
language and literature is not only the translation of literary works, but also the application of English knowledge in literary works. This is not only the core of English language and literature teaching, but also the core way for students to have a thorough understanding of literary works. To interpret and interpret the application of English knowledge in literary works reasonably, accurately and comprehensively, it is necessary to make a thorough study of literary works from the perspectives of literary analysis, cultural analysis, historical analysis and psychological analysis, so as to give a thorough explanation to students in teaching practice. Enable students to develop a thorough understanding of English knowledge. It avoids the emergence of "concrete" problems in English language and literature teaching, realizes the teaching significance of English language and literature teaching and enables students to accurately acquire English knowledge and English cultural connotation.

\section{An optimization strategy for English language and literature teaching based on "abstract and specific" dimensions}

\subsection{The formulation of English language and literature teaching contents}

The formulation of teaching content of English language and literature is not only the content of teachers' work before class, but also the foundation of realizing the teaching effect of English language and literature. Therefore, teachers should adhere to the principle of excavating the effectiveness of English language and literature education value, and make the teaching content scientific and humanized. Scientificalization refers to the analysis and interpretation of the connotation of literary works in the formulation of teaching content, and the reasonable choice based on the teaching objectives. At the same time, teachers should master their literary and cultural characteristics, and integrate the two knowledge points into the teaching content, so as to help students understand literary works and expand their cultural knowledge. Humanization refers to the process of teaching content should be combined with students' cognitive ability to conduct a comprehensive assessment, to ensure that students can accurately understand the content of knowledge after the teacher's explanation, not beyond the scope of students' cognitive burden on students. After the selection of teaching content, in order to enhance students' interest in literary knowledge, teachers should prepare corresponding teaching materials, and formulate corresponding audio-visual applications in classroom teaching activities. Then the abstract teaching content can be presented in front of the students to generate learning motivation, and then effectively mobilize students'autonomous learning ability to explore and acquire English knowledge. At the same time, teachers should design the discourse form of classroom teaching to a certain extent. In the process of narrating literary works, teachers should incorporate personalized language so that students can easily recognize the content of knowledge.

\subsection{Classroom interaction in English language and Literature Teaching}

In the classroom teaching of English language and literature, teachers should actively carry out interactive teaching in order to strengthen the particularity and fundamental purpose of English knowledge education. The interaction and cooperation between teachers and students on the content of knowledge as well as between students are of great importance not only in English language and literature teaching, but also in all English teaching models. Only through the interactive exchange of knowledge and information can we maximize the students'autonomous learning ability. Then the cognitive thinking activities of students can maximize the analysis and judgment of knowledge information and form new knowledge in the students'knowledge structure. Therefore, in the classroom teaching activities of English language and literature, teachers should give full attention to interactive communication and give full class hours.

In the initial stage of classroom teaching, teachers explain the theoretical nature of knowledge content. In this process, teachers should adhere to the principle of thoroughness in English language and literature teaching practice. Systematic explanations should be made from the dimensions of English language knowledge, literature, history and culture, and basic literary knowledge. Attention 
should be paid to the conciseness and conciseness of discourse forms so as to avoid the spread of students' cognitive thinking activities. The teaching of theoretical knowledge should occupy about half of the total class hours. If the class hours are too long, students' cognition will be too theoretical, but if the class hours are too long, it will be difficult for students to understand the content of knowledge thoroughly. After the explanation of the theoretical knowledge, the teacher should start the interactive communication between the knowledge content and the students. The core of this process is to make the knowledge content practical, so that the students can quickly recognize the practicality of the knowledge content. The form of interaction can be discussion, debate, lecture, etc. Interactive communication is mainly to hone students' English listening and speaking ability, and indirectly exercise students' communication ability and cooperation ability. It is an important strategy to improve students' English practical ability to carry out interactive teaching rapidly after the end of theoretical knowledge teaching. Teachers should take the application of English knowledge as the core of interaction, so that students can master the application methods of English knowledge in the process of interaction. In view of the particularity of English language and literature teaching, teachers should maximize the advantages of English language and literature in English cultural knowledge to enrich students' understanding of English knowledge. Therefore, in the classroom teaching part, students can also be arranged to express certain cultural concepts in the form of writing. This teaching process not only integrates the use of English knowledge but also the use of cultural knowledge. It also plays a role in cultivating students' knowledge and quality.

\subsection{Life oriented practice teaching mode of English language and Literature}

It is not only an important and effective teaching strategy, but also a developing direction of foreign language education in our country in the new form. The life-oriented teaching of English language and literature means that the process of students' knowledge acquisition should be connected with the students' reality in the teaching activities. It can not only significantly enhance students' cognition of English knowledge, but also significantly enhance students' ability to apply English in practice and solve problems in the real environment. Therefore, the educational value of English knowledge can be shown in the students' consciousness, and the students' enthusiasm for learning English knowledge can be enhanced. It is difficult for traditional English teaching activities to get out of the books and the classroom, and it is difficult for students to improve their English practice in a theoretical way. After the teaching of English language and literature is put into practice, it not only realizes the education of students' English knowledge, the practical training of English knowledge and the cultivation of cultural connotation, but also promotes the students' understanding and cognition of real life and forms a correct attitude towards life. Therefore, to make English language and literature teaching live is the core strategy to improve the quality of English language and literature teaching.

The daily life of English language and literature teaching is strictly the practice of English teaching. Teachers need to design scientifically and carefully the content, procedure, object and goal of the activities before the practical activities are carried out. In order to ensure the safety and effectiveness of life teaching in English language and literature. The activities should focus on the English language and literature, refine the story structure of the literary works, and arrange them into a stage play or drama form. They can also be designed in the form of small programs. The lines are used in literary works and adapted appropriately, and the roles are played by students. The whole repertoire is performed in the form of English listening and speaking, and students are required to supplement the corresponding verbal expressions and actions. Because students have a good understanding of the connotation and storytelling of literary works, they can fully grasp and recognize the practicality of English knowledge in the process of practical application of English language. And then maximized the acquisition of English knowledge. In the process of teaching and enjoying themselves, students can have a comprehensive grasp of English knowledge and culture, and enhance their interest in English learning. In addition, the life-style practical teaching model of English language and literature is not fixed, but can be designed according to the situation of teaching resources and students' actual conditions. 


\section{Conclusion}

Through the study of "abstraction and concreteness" in the teaching of English language and literature, it can be concluded that the scope of excavating the educational value of English language and literature is too broad, which will bring great pressure to students' cognitive thinking and make them think that the content of English language and literature is too abstract. If the scope of the excavation is too small, the students' cognition can only stay in the specific part of the surface of English language and literature, and can not be further extended to acquire its meaning, thus losing its teaching significance. Then it puts forward the basic principles and strategies to solve the problem. It is an effective way to optimize the teaching of English language and literature by setting up the teaching contents, strengthening the interaction of classroom teaching and carrying out the practical activities of life after class. Abstraction and concreteness are two dimensions of the study of English language and literature teaching. They are the ways to explore the essence of teaching phenomena. They are also the angles to solve the problems of English language and literature teaching and to improve the quality of English language and literature teaching. Adhering to the principles of the effectiveness of Value Mining in English language and literature education and the thoroughness of English language and literature teaching practice, strengthening the interaction and practicality in the process of teaching activities and maximizing the educational value of English language and literature are the core strategies to improve students' English proficiency.

\section{References}

[1] Han Lina; Ho Jingyi. Teaching Methods of English Language and Literature: A Review of English Language and Literature Research [J]. Contemporary Educational Science, 2015, 03: 21-23.

[2] Zhan Limin. Literature Course Combining Language Teaching with Literature Teaching--Literature Teaching for English Majors [J]. Hubei Social Sciences, 2009 (08): 31-34.

[3] Cai Jingmei. A Brief Analysis of the Influence of English Language and Literature on College Students' English Acquisition Ability [J]. Journal of Jiyuan Vocational and Technical College, 2015, 02: 37-39.

[4] Li Yan. The Role of English Language and Literature in Developing Students' Language Ability [J]. English Plaza, 2016, 05: 18-20.

[5] Ji Jiemei. The Importance of English Literature in English Teaching [J]. Journal of Social Sciences, Harbin Normal University, 2013 (04): 37-40. 